\title{
Mental comparisons for ordered information on abstract and concrete dimensions
}

\author{
STEPHEN M. KERST and JAMES H. HOWARD, JR. \\ Catholic University of America, Washington, D.C. 20064
}

\begin{abstract}
Subjects compared pairs of animal, country, and car names, which had been ranked along concrete (perceptual) and abstract (nonperceptual) dimensions by an independent group (e.g., animals were rated for size and ferocity). For judgments based on abstract and concrete dimensions, comparison time decreased as the difference between the rated scale values of the items increased. Furthermore, comparison time was better predicted by the interval than by the ordinal distance between test pairs. This finding suggests that judgments are based on some kind of long-term memory representation which has analog characteristics, in that it preserves more than rank-order information. The question of whether one common memory code or two separate codes are involved in comparisons based on abstract and concrete dimensions is discussed. Three alternative models are proposed and the role of visual imagery in memorial comparisons is considered.
\end{abstract}

Moyer (1973) and others (Moyer \& Bayer, 1976) have investigated the manner in which subjects make comparisons among symbols which represent concrete objects in long-term memory. Subjects were first asked to rank animal names in terms of the relative size of the animal. In a task where subjects were later shown pairs of animal names and asked to judge which of the two animais was larger (Moyer, 1973), it was found that reaction time (RT) decreased as the difference between the rated sizes of the animals increased. These results are similar to those obtained when subjects compare the sizes of physical stimuli which are actually presented (Curtis, Paulos, \& Rule, 1973).

The similarity between perceptual and memorial comparisons under these conditions led Moyer to suggest that subjects make some kind of "internal psychophysical judgment" among memory representations. The representations have analog or continuous characteristics, in that they reflect the relative sizes of the objects they represent, rather than simply categorizing the objects in discrete linguistic terms, such as large, medium, or small. Similarly, Shepard (1975) and others (Shepard \& Chipman, 1970; Shepard \& Podgorny, in press) propose that a kind of secondorder isomorphism exists between mental representations of objects and the objects themselves. Although the parts of internal representations may not have a one-to-one correspondence with the parts of the actual

The authors thank Darlene Howard, Bruce Ross, and an anonymous reviewer for their comments on an earlier draft of this manuscript. Thanks are also due to Nick Geleta and Patricia Wolskee for their assistance in collecting and reducing the data. Requests for reprints should be addressed to Stephen M. Kerst, Boys Town Center for the Study of Youth Development, the Catholic University, Washington, D.C. 20064. This research was partially supported by the Boys Town Center for the Study of Youth Development. objects (first-order isomorphism), the relationships which hold among the objects are reflected in the relationships which exist among the representations. For example, Shepard and Chipman (1970) asked subjects to compare states of the United States in terms of their similarity of shape. Data from a multidimensional scaling study produced similar scaling solutions whether subjects actually viewed a map while they compared the states or they made the comparisons from memory. Such results are congruent with the notion that analog information is preserved in memory for perceptual stimuli.

Paivio (1975) argues that visual imagery is the mode in which such analog information is retained about concrete objects and events. In Paivio's $(1971 ; 1974)$ dual-coding theory, the imagery and verbal systems are viewed as independent but connected domains for representing knowledge. The verbal system deals with discrete linguistic representations, while the imagery system is closely related to perceptual knowledge. According to the dual-coding model, subjects in Moyer's (1973) experiment could make size judgments about the pairs of animal names by shifting from a verbal to an imagery code and comparing analog representations which included information about the relative sizes of the animals.

Recently, Paivio (1975) extended Moyer's (1973) study to test explanations based on subjects' use of overlearned verbal labels as the basis of comparison. As in Moyer's (1973) study, RTs varied inversely with the difference between the rated size of the objects to be compared. In fact, RTs were negatively related to the ratios of the rated sizes of the objects, when ratings were obtained from an independent sample of subjects. This result suggests that subjects were using analog representations which yielded interval information about the degree to which objects differed in size, 
in addition to knowledge of the ordinal rankings of the stimuli on the dimension of size.

In a recent study, Moyer and Bayer (1976) separated ordinal and interval components of the comparison process and found that subjects used both kinds of information in making size judgments in memory. Subjects learned to associate nonsense syllables to circles in either a small size range (11.17 $\mathrm{mm}$ in diam) or a large size range (11-23 $\mathrm{mm}$ in diam). When subjects compared the syllables in terms of the size of the circles to which they were associated, both the ordinal and the absolute size differences between stimuli affected RT. Moyer and Bayer (1976) refer to the relationship between size differences and comparison RT as the "symbolic-distance effect" (SDE) and state the effect as follows: "The time needed to compare two symbols varies inversely with the distance between their referents on the judged dimension."

The central question in the present experiment is whether the SDE is found for memorial comparisons along abstract-nonperceptual as well as concreteperceptual dimensions. The terms "abstract" and "concrete" are commonly distinguished in the psychological literature (e.g., Paivio, Yuille, \& Madigan, 1968). Words referring to physical characteristics of objects, materials, or persons are termed concrete (e.g., size), while words referring to concepts which cannot be directly experienced by the senses are termed abstract (e.g., ferocity, power, cost). In principle, comparisons made along a concrete dimension such as size can be based on perceptual information, whether available only in memory or from stimuli which are actually presented. One's knowledge of such information could derive either from direct experience with the actual objects in a variety of contexts (e.g., viewing common animals and cars) or indirectly from pictures or graphic representations of the objects (e.g., in viewing pictures of animals or maps of countries). Indeed, Shepard and Chipman's (1970) finding, that judgments of the similarity of the shapes of states from memory were extremely similar to judgments made when a map was provided, supports the proposition that maps rather than verbal descriptions provide the primary basis for certain geographic knowledge.

In contrast, comparisons along an abstract nonperceptual dimension require subjects to make inferences which go beyond any simple, directly perceptible attribute of the objects. For example, while one can imagine a perceptual correlate of ferocity (e.g., prominent teeth), the use of such a single characteristic in judging ferocity would lead to substantial judgment error. Neither the beaver's large teeth nor the relatively large size of a cow would lead to a reliable estimate of their ferocity. A characteristic such as temperament, which has no obvious perceptible cue, is a more important indicator of ferocity than is any simple perceptual attribute. If it were found that abstract comparisons yielded an SDE, the distinction between imagery and verbal processes, in terms of analog vs discrete representations (Paivio, 1975), would have to be revised. On the other hand, the failure to find an SDE with abstract comparisons would support the Paivio $(1971,1974)$ dual-coding model.

There is some evidence that abstract as well as concrete comparisons reveal the SDE (Potts, 1972, 1974). However, these comparisons were based on arbitrary linear orderings along abstract dimensions, such as friendliness or intelligence, which were learned from paragraphs presented in the experiment (e.g., "The clam was friendlier than the duck, the fish was friendlier than the frog, and the frog was friendlier than the clam"). In a similar recent experiment, Holyoak and Walker $(1976)^{1}$ found an SDE when subjects compared terms from the natural language scales of time (e.g., hour, minute, second), quality (e.g., excellent, good, average), and temperature (e.g., warm, cool, cold). As in Potts' $(1972,1974)$ studies involving contrived orderings, subjects were asked to confirm their agreement with the ordered scale items before making their comparisons. In addition, the order of the terms on the scales investigated was determined either by precise definition (e.g., there are $60 \mathrm{sec}$ in a minute, $60 \mathrm{~min}$ in an hour, etc.), or by linguistic convention (e.g., warm is hotter than cold, excellent is better than average).

In contrast to these studies, the order of terms on the abstract dimensions used in the present study was determined by subjects' conceptual knowledge of the world, that is, knowledge about the ferocity of animals, the cost of cars, and the military power of nations. Subjects were not asked to agree to an ordered array of terms prior to the experiment. Clearly, then, the present experiment differed from previous work in that both abstract and concrete comparisons were based on knowledge of the world rather than on (1) a contrived order memorized for the experiment, or (2) an agreed-upon order based on linguistic usage or definition.

A second purpose of the present study was to extend and further test Paivio's (1975) and Moyer and Bayer's (1976) finding that comparison times for concrete pairs depend on the interval as well as ordinal distance between items. The relation of both interval and ordinal scale distances to comparison RT were assessed for abstract as well as concrete judgments.

\section{METHOD}

\section{Materials}

Three categories (animals, countries, and cars) of six stimulus terms each were selected from a larger sample, on the basis of a preliminary scaling study. In the preliminary study, 32 undergraduates rated eight items from each of seven sets, using a 5 -point scale. For example, the subjects were asked to rate a set of animal names "in terms of their physical size, where: 5 represents the largest size, 4 represents above average size, 
Table 1

Mean Ratings and Standard Deviations for All Stimulus Items

\begin{tabular}{|c|c|c|c|c|c|c|c|c|c|}
\hline & & Mean & SD & & Mean & SD & & Mean & $\mathrm{SD}$ \\
\hline \multirow{3}{*}{ Concrete } & \multicolumn{3}{|c|}{ Animals (Size) } & \multicolumn{3}{|c|}{ Countries (Size) } & \multicolumn{3}{|c|}{ Cars (Size) } \\
\hline & $\begin{array}{l}\text { Mouse } \\
\text { Fox } \\
\text { Dog } \\
\text { Sheep } \\
\text { Cow } \\
\text { Bear }\end{array}$ & $\begin{array}{l}1.22 \\
2.41 \\
2.66 \\
3.00 \\
4.25 \\
4.81\end{array}$ & $\begin{array}{l}.85 \\
.53 \\
.51 \\
.44 \\
.62 \\
.41\end{array}$ & $\begin{array}{l}\text { Israel } \\
\text { Japan } \\
\text { England } \\
\text { Mexico } \\
\text { America } \\
\text { Russia }\end{array}$ & $\begin{array}{l}1.47 \\
2.25 \\
2.53 \\
3.13 \\
4.25 \\
4.97\end{array}$ & $\begin{array}{l}.61 \\
.83 \\
.71 \\
.57 \\
.57 \\
.14\end{array}$ & $\begin{array}{l}\text { MG } \\
\text { VW } \\
\text { Toyota } \\
\text { Ford } \\
\text { Pontiac } \\
\text { Cadillac }\end{array}$ & $\begin{array}{l}1.09 \\
1.91 \\
2.31 \\
3.41 \\
3.78 \\
4.75\end{array}$ & $\begin{array}{l}.30 \\
.57 \\
.54 \\
.46 \\
.49 \\
.44\end{array}$ \\
\hline & \multicolumn{3}{|c|}{ Animals (Ferociousness) } & \multicolumn{3}{|c|}{ Countries (Military Power) } & \multicolumn{3}{|c|}{ Cars (Cost) } \\
\hline Abstract & $\begin{array}{l}\text { Mouse } \\
\text { Sheep } \\
\text { Cow } \\
\text { Dog } \\
\text { Fox } \\
\text { Bear }\end{array}$ & $\begin{array}{l}1.44 \\
1.72 \\
1.91 \\
3.16 \\
3.69 \\
4.94\end{array}$ & $\begin{array}{l}.79 \\
.71 \\
.75 \\
.85 \\
.66 \\
.20\end{array}$ & $\begin{array}{l}\text { Mexico } \\
\text { Japan } \\
\text { Israel } \\
\text { England } \\
\text { Russia } \\
\text { America }\end{array}$ & $\begin{array}{l}1.81 \\
2.81 \\
3.16 \\
3.28 \\
4.78 \\
4.94\end{array}$ & $\begin{array}{l}.69 \\
.85 \\
.82 \\
.72 \\
.49 \\
.20\end{array}$ & $\begin{array}{l}\text { VW } \\
\text { Toyota } \\
\text { Ford } \\
\text { Pontiac } \\
\text { MG } \\
\text { Cadillac }\end{array}$ & $\begin{array}{l}1.47 \\
2.06 \\
2.88 \\
3.34 \\
3.59 \\
4.69\end{array}$ & $\begin{array}{l}.56 \\
.71 \\
.58 \\
.56 \\
.94 \\
.44\end{array}$ \\
\hline
\end{tabular}

3 represents average size, 2 represents below average size, and 1 represents the smallest size." Each item was rated independently on a concrete (e.g., size) and an abstract (e.g., ferocity) dimension. Mean ratings and judgment-consistency measures (i.e., standard deviations) were computed for each item and each dimension. The three sets showing the highest overall consistency (i.e., lowest standard deviations) on both the concrete and abstract dimensions were selected for use in the experiment. In addition, six items were chosen from each set to provide maximum consistency and scale range. All test items were common English nouns, ranging in length from two to eight letters. The stimulus items are presented in Table 1 with their mean ratings and standard deviations. While the dimensions investigated were selected on intuitive grounds, subjects' concreteness ratings of the chosen dimensions tend to confirm the authors' intuitions (Paivio, Yuille, \& Madigan, 1968). On a 7-point scale, where "apple" was rated 7.0 and "fact" was rated 3.3, our terms "power" and "cost" were rated 2.7 and 3.4 , respectively. The ratings of "hostility" (2.2) and "vigor" (2.6) provide a rough indication of the abstract nature of the ferocity dimension.

\section{Subjects}

Subjects were 15 volunteer students and recent graduates of the Catholic University, who were paid $\$ 2$. No experimental subject served in the preliminary scaling study.

\begin{abstract}
Apparatus
All experimental events were controlled by a Digital Equipment Corporation PDP-8E computer. Subjects were tested individually in a sound-attenuated booth, containing an Applied Digital Data Systems Consul-580 CRT terminal. Stimulus pairs were presented on the CRT screen and subjects responded by pressing one of two adjacent buttons on the keyboard (the " 1 " and " 2 " keys on a 3 by 4 numerical pad). Test pairs were presented directly beneath a visual warning signal. Regardless of item length, individual items in the pair were always displayed at the same location on the screen. Each pair subtended a maximum visual angle of approximately $3 \mathrm{deg}$, and characters were displayed serially at a rate of approximately $1 \mathrm{msec}$ per character. Reaction times were recorded using a computercontrolled $5-\mathrm{kHz}$ crystal clock.
\end{abstract}

\section{Procedure}

Immediately prior to the experiment, subjects read instructions that described the task and each of the three categories and two judgment dimensions to be tested. They were asked to respond by pressing the key on the same side (left or right) as the pair member having the greater value on the tested dimension. For example, if the pair "dog bear" was presented for a ferocity judgment, the subject would press the right key, indicating that a bear is more ferocious than a dog. Before beginning the experiment, subjects responded to 15 practice trials, involving items differing on the dimension of height.

Test pairs were presented in 30-trial blocks, with each of the possible pairs for a particular judgment dimension (e.g., animal size) appearing twice, counterbalanced for side of presentation. Trials were randomized within blocks, with the constraint that all 15 pairs appear once before any was repeated. Block order was determined haphazardly for each subject. Eight subjects responded to the three sets on the abstract dimension first, while seven subjects responded on the concrete dimensions first. All subjects made both abstract and concrete judgments for each of the three sets, for a total of 180 trials per subject. Each trial began when a ready message was displayed, indicating the current judgment dimension (e.g., "Which is more ferocious?"). After a 1.5-sec delay, the test pair was presented directly below the warning message. Following the subject's response, the screen was cleared and the next trial began after a 2.5 -sec intertrial interval. After every 15 judgments, subjects were allowed to take a break before continuing. Subjects moved on to the next trial block by pressing the space bar when they were ready. The entire session lasted less than $30 \mathrm{~min}$.

\section{RESULTS}

\section{Preliminary Analyses}

In order to eliminate extreme RT scores from the analysis, an overall mean RT and variance was computed across all subjects and conditions in the experiment. In all subsequent analyses, individual RTs three or more standard deviations from the overall mean (i.e., greater than $4,617 \mathrm{msec}$ ) were discarded. Twenty-three of the 2,700 trials ( 10 concrete and 13 abstract) were eliminated on this basis. Further, in order to insure that only reliable judgments were considered, responses inconsistent with the preliminary scaling data were eliminated from further analysis. Overall, consistency was high, with subjects making "correct" judgments on $91.4 \%$ and $85.0 \%$ of the pairs for the concrete and abstract dimensions, respectively. Mean RTs collapsed across 
Table 2

Mean Reaction Times (in milliseconds) Across Subjects for All Pairs of Items

\begin{tabular}{|c|c|c|c|c|c|c|c|c|c|c|c|c|}
\hline & & & \multicolumn{5}{|c|}{$\begin{array}{c}\text { Concrete } \\
\text { Item Rank }\end{array}$} & \multicolumn{5}{|c|}{$\begin{array}{l}\text { Abstract } \\
\text { Item Rank }\end{array}$} \\
\hline & & & 1 & 2 & 3 & 4 & 5 & 1 & 2 & 3 & 4 & 5 \\
\hline Animals & $\begin{array}{l}\text { Item } \\
\text { Rank }\end{array}$ & $\begin{array}{l}2 \\
3 \\
4 \\
5 \\
6\end{array}$ & $\begin{array}{r}1081 \\
952 \\
1060 \\
1061 \\
994\end{array}$ & $\begin{array}{l}1366 \\
1240 \\
1049 \\
1053\end{array}$ & $\begin{array}{l}1269 \\
1023 \\
1043\end{array}$ & $\begin{array}{l}1274 \\
1195\end{array}$ & 1199 & $\begin{array}{l}1653 \\
1787 \\
1267 \\
1213 \\
1059\end{array}$ & $\begin{array}{l}1810 \\
1288 \\
1224 \\
1077\end{array}$ & $\begin{array}{l}1309 \\
1265 \\
1010\end{array}$ & $\begin{array}{l}1242 \\
1066\end{array}$ & 1259 \\
\hline Cars & $\begin{array}{l}\text { Item } \\
\text { Rank }\end{array}$ & $\begin{array}{l}2 \\
3 \\
4 \\
5 \\
6\end{array}$ & $\begin{array}{r}1498 \\
1515 \\
962 \\
1143 \\
845\end{array}$ & $\begin{array}{r}1122 \\
968 \\
994 \\
860\end{array}$ & $\begin{array}{r}1206 \\
1099 \\
908\end{array}$ & $\begin{array}{l}1102 \\
1023\end{array}$ & 992 & $\begin{array}{r}1677 \\
1137 \\
1159 \\
1428 \\
954\end{array}$ & $\begin{array}{l}1420 \\
1281 \\
1368 \\
1000\end{array}$ & $\begin{array}{r}1549 \\
1347 \\
948\end{array}$ & $\begin{array}{l}1443 \\
1033\end{array}$ & 1102 \\
\hline Countries & $\begin{array}{l}\text { Item } \\
\text { Rank }\end{array}$ & $\begin{array}{l}2 \\
3 \\
4 \\
5 \\
6\end{array}$ & $\begin{array}{r}1969 \\
1452 \\
1478 \\
998 \\
1192\end{array}$ & $\begin{array}{l}1760 \\
1463 \\
1014 \\
1084\end{array}$ & $\begin{array}{l}1674 \\
1193 \\
1084\end{array}$ & $\begin{array}{l}1092 \\
1124\end{array}$ & 1264 & $\begin{array}{l}1481 \\
1367 \\
1568 \\
1085 \\
1003\end{array}$ & $\begin{array}{l}1441 \\
1386 \\
1214 \\
1171\end{array}$ & $\begin{array}{l}1464 \\
1102 \\
1089\end{array}$ & $\begin{array}{l}1176 \\
1233\end{array}$ & 1391 \\
\hline
\end{tabular}

subjects for every pair on each judgment dimension appear in Table 2 .

\section{Symbolic-Distance Analysis}

Mean RTs were determined for each condition and each subject in the experiment by collapsing across the two presentations of each test pair. Mean RTs were then computed for each ordinal distance for all conditions and subjects. Distance ranged from 1 , for immediately adjacent pairs, to 5, for the maximally disparate pair. The data were submitted to a three-way (symbolic distance by category by concreteness) repeated measures analysis of variance (Myers, 1966). The mean RTs for judgments on concrete and abstract dimensions at each ordinal distance are displayed in Figure 1.

Two findings are evident in Figure 1. First, there is a significant overall tendency for response time to decrease as symbolic distance increases $[F(4,56)=19.08$, $\mathrm{p}<.001]$. Second, subjects tend, on the average, to require more time ( $81 \mathrm{msec})$ for abstract judgments than for concrete judgments $[F(1,14)=7.56, p<.025]$. It is interesting, however, that the concreteness effect is absent at Ordinal Distance 5, where the mean RTs for concrete and abstract judgments are virtually identical. However, the Distance by Concreteness interaction did not reach statistical significance $[F(4,56)=2.37$, $p>.05]$. Since the means at Ordinal Distance 5 are based on the smallest number of pairs (one pair per subject) and are, therefore, less reliable than the means at the other distances, it is likely that the result reflects a spurious decrease in the mean RT at Distance 5 for the abstract judgments. In general, therefore, mean RT is a monotonic decreasing function of ordinal symbolic distance for both abstract and concrete unidimensional comparisons involving natural categories.
Two additional effects were significant in the analysis of variance described above. Overall, subjects required $1,105,1,154$, and $1,230 \mathrm{msec}$ for judgments involving the cars, animals, and countries, respectively. The difference among categories was statistically reliable $[F(2,28)=5.64, p<.01]$. Post hoc analysis, using Duncan's Multiple Range Test $(\alpha=.05)$ revealed reliable

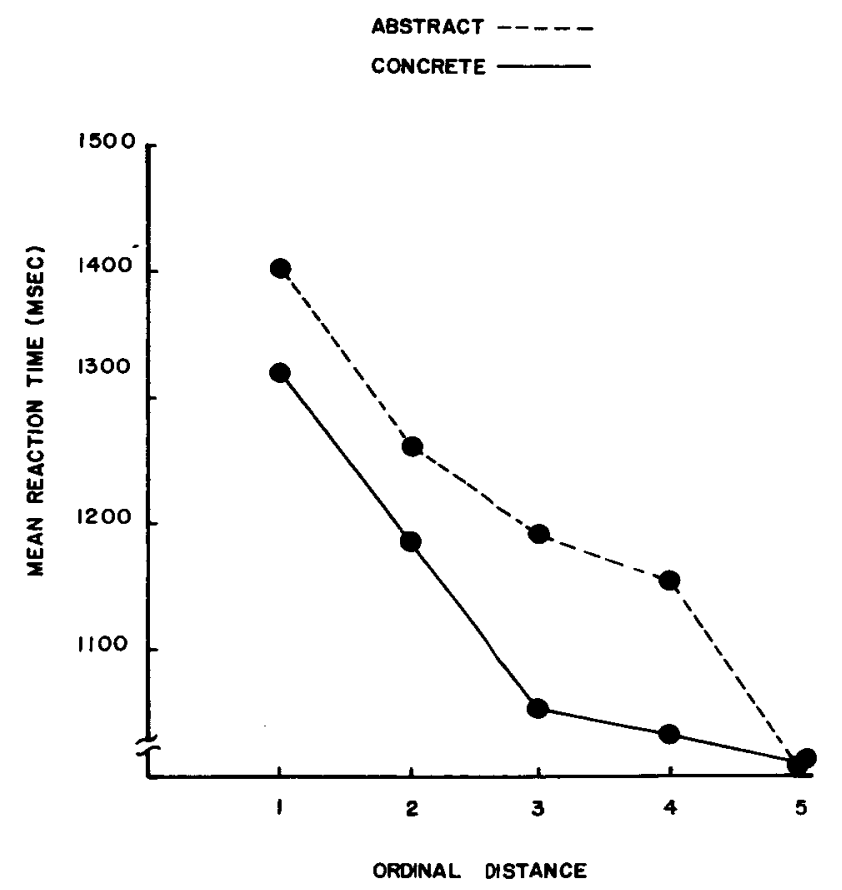

Figure 1. Mean RTs for judgments on concrete and abstract dimensions at each ordinal distance. Note-All pairs whose members differed by 1 unit are included in Ordinal Distance 1, likewise for Distances 2-5. 
RT differences between country and animal judgments and between car and country judgments; however, no significant difference was observed between the animal and car judgments. It was also evident that the RT difference between concrete and abstract comparisons was not identical for the three categories investigated. The effect was revealed in a significant Category by Concreteness interaction $[F(2,28)=4.84, p<.025]$. While the concrete comparisons were more rapid for the car and animal sets (by 143 and $130 \mathrm{msec}$, respectively), the abstract comparisons were slightly faster than the concrete comparisons $(31 \mathrm{msec})$ for the country set. Although the concreteness effect varies with the category investigated, it is important to note that the distance effect remains constant, regardless of the magnitude of the concreteness effect [i.e., the Distance by Concreteness by Category interaction was not statistically significant: $F(8,112)=1.66]$.

\section{Ordinal vs Interval Distance Analysis}

In the above analyses, the symbolic-distance values for each pair were based on the ordinal distance between the pair members. As indicated in the introduction, some have argued that the interval distance between items more accurately reflects the subjective distance separating the items in memory (cf. Shepard \& Podgorny, in press). In order to test this possibility in the present data, interval distances were computed for each pair on each condition, using the scale values presented in Table 1 from the preliminary scaling study. For example, while the ordinal distance for size judgments between "mouse" and "fox" is 1 , the interval distance for this pair is 1.19. Mean RTs were computed across all subjects for each of the fifteen pairs on each condition. Pearson product-moment correlations were then computed between both interval and ordinal distance values and the mean RTs for each pair. The correlation coefficients for each condition are displayed in Table 3. Note that, while all correlations were significantly greater than 0 at the .025 level, in all cases, the correlation coefficient was greater when the interval distances were used than when the ordinal distances were used. This result is observed for both the abstract and concrete judgments. The effect was further investigated at the individual subject level by comparing the correlations observed between interval and ordinal distances and mean RT for each subject

Table 3

Correlations Between Scale Distances and Mean RTs for Abstract and Concrete Comparisons on Each Dimension

\begin{tabular}{llccc}
\hline & & Animals & Countries & Cars \\
\hline \multirow{2}{*}{ Concrete } & Interval & -.71 & -.70 & -.56 \\
& Ordinal & -.65 & -.57 & -.53 \\
\multirow{2}{*}{ Abstract } & Interval & -.78 & -.77 & -.70 \\
& Ordinal & -.55 & -.62 & -.55 \\
\hline
\end{tabular}

and condition. For the concrete judgments, interval correlations were larger in 32 of 45 comparisons, while, for the abstract judgments, the interval correlations were larger in 35 of the 45 comparisons. A sign test indicated that the effect was highly significant for both the concrete and abstract judgments $(z=2.68$, $\mathrm{p}<.01$, and $\mathrm{z}=3.58, \mathrm{p}<.001$, respectively). These findings suggest that, in the present study, the interval distances between pairs as computed from the preliminary scaling study provide a better predictor of mean RTs than do the ordinal distances. ${ }^{2}$

Although the symbolic-distance effect is of primary interest, response times in a mental comparison task have been observed to depend on other characteristics of the test pair as well. For example, Moyer and Bayer (1976) have recently reported that response time in a memorial size-comparison task depends not only on the distance between the pair items, but also on the relative magnitude of the larger pair member. The greater the magnitude of the larger item, the faster the response time. Moyer and Bayer have interpreted this to indicate that subjects locate size information in memory using a serial, large-to-small search process. While the present study was not designed to examine this effect, examination of the mean reaction times for individual pairs revealed a trend very similar to the effect reported by Moyer and Bayer. Within each symbolic distance, mean RTs increased with distance from the stimulus of greatest magnitude. These data, collapsed across all experimental conditions, are displayed in Figure 2. While this analysis is preliminary at best, it does suggest that the size effect reported by Moyer and Bayer occurs for judgments involving preexperimental knowledge, as well as for the perceptual size differences learned in their study.

\section{DISCUSSION}

The central finding in the present experiment is that the symbolic-distance effect occurred for abstract as well as for concrete memorial comparisons. Mental comparison time was observed to decrease as the rated difference between two items increased for both abstract (e.g., ferocity) and concrete (e.g., size) dimensions. Further, the interval scale distances between terms predicted comparison times more accurately than did simple ordinal distances. This suggests that the comparisons were not based merely on the ordinal rankings of the stimuli along a scale, but rather on the precise, subjective distances between the compared items.

The finding that mental comparison times reflect the degree to which terms differ along a dimension poses problems for theories which describe the longterm memory code in terms of discrete language-based constructs. For example, the type of linguistic size code proposed by Trabasso and Riley (1975) (e.g., 


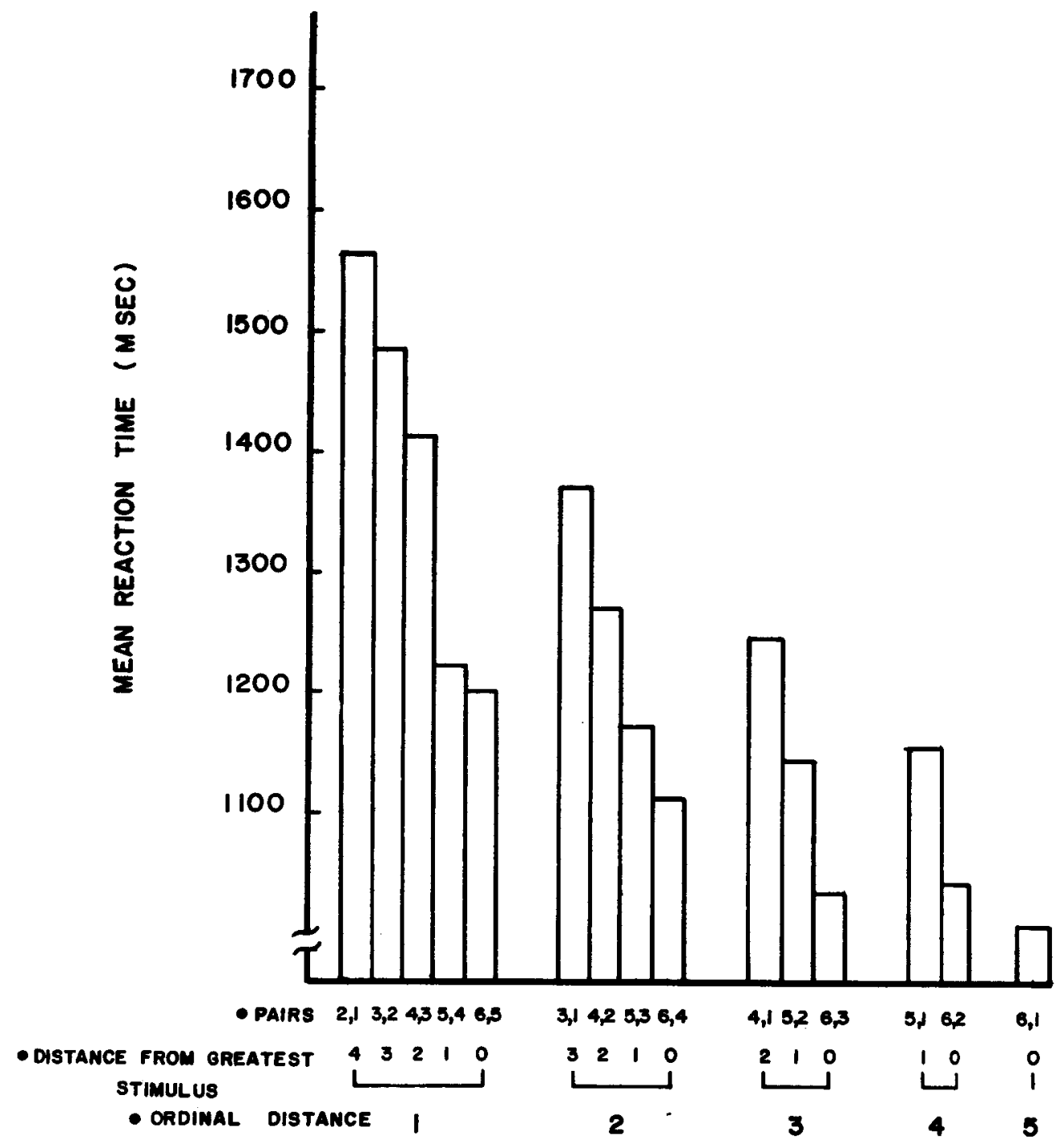

Figure 2. Mean RTs for individual pairs plotted in terms of distance from stimulus of greatest magnitude.

very small, small, large, and very large) to account for comparisons based on linear orders learned during an experiment cannot easily explain the result that subjects preserve more than ordinal scale information. The linguistic code models have particular difficulty in the present study, as in Paivio's (1975) study, where subjects compared stimulus pairs sampled from relatively large natural categories. Since, in both studies, subjects could not anticipate which specific comparisons they would be asked to make, any discrete linguistic code used to discriminate items would have to be relatively finegrained to distinguish the many possible pairs. Furthermore, as Moyer and Bayer (1976) pointed out, when such theories are modified by the addition of finer gradations of features (e.g., large, large + , larget+, etc.), they begin to resemble the alternative, analog memory code theories (e.g., Moyer, 1973).
The present data suggest that some kind of analog memory representation-a code which represents continuous rather than discrete information-is involved in the comparison process for both abstract and concrete stimulus characteristics. At least three alternative formulations are consistent with the present findings: an amodal single-code model, an independent dual-code model, and an imagery-translation model. Each possibility will be briefly examined below.

First, one could argue from the present data that knowledge of the world, whether perceptual-concrete or abstract, is represented in an amodal form, having analog properties. In other words, both abstract (e.g., ferocity) and concrete (e.g., size) information about any item is represented in an identical code that is not tied to any particular perceptual modality. According to this theory, similar or identical mental 
processes would underlie both concrete and abstract comparisons, yielding a symbolic-distance effect in both cases.

Second, it is possible that parallel, independent memory codes exist for concrete and abstract information. For example, a visual imagery code could represent concrete perceptual information while an amodal code could underlie abstract information. The mental operations involved in the comparison process may differ for abstract and concrete judgments; however, the temporal characteristics of these processes would be similar. This model reflects a revision of Paivio's (1975) dual-coding position, which assumes a visual imagery code for concrete objects and events and a verbal code for linguistic information. Paivio's (1975) finding that a symbolic-distance effect occurs both for visual psychophysical comparisons and memorial comparisons based on the concrete dimension of size has been interpreted as support for the imagery portion of the dual-coding model. Since, in the present study, the symbolic-distance effect was also obtained for abstract comparisons, the effect in itself cannot be taken as a unique property of the imagery system which sets it apart from the verbal system. Rather, the case for the role of visual imagery in the comparison process must rest on evidence other than the symbolicdistance effect. Paivio (1975) has presented additional compelling support for his position with the finding that size comparisons based on information in long-term memory are faster when the items are presented as pictures rather than as words. He argues that this should be so if comparisons are based on imagery, since he assumes that visual memory codes are activated more directly by pictures than by names. In light of the present data, a dual-code model could be proposed in which imagery and abstract semantic codes involve different kinds of memory representations, both of which have analog properties.

Third, one could argue that an analog imagery code provides the basis for both abstract and concrete comparisons. Abstract information, which may be stored in some nonimagery form, is converted to a metaphorical analog image for purposes of comparison. For example, an abstract representation of "military power" might be transformed into an image of an assembly of cannon or soldiers. According to this model, an identical image-based comparison process would underlie both abstract and concrete comparisons; however, an additional translation process would be required for the abstract judgments. Some support for this translation process can be found in the present data, where abstract comparisons, which would require additional time for the translation, took longer on the average than concrete comparisons. This interpretation is highly speculative, however, since other differences between the abstract and concrete dimensions examined (e.g., differences in familiarity and the spread of terms along the scale) could also account for the results.
A basic weakness of the imagery-translation model is that, in order to construct an image that represents the relative scale value of an abstract term, the speci. c scale values must already be represented within the nonimagery memory code. For example, how does one know the number of soldiers that should be imaged to represent the military power of a particular country, unless this kind of information is already present in the abstract system?

The major distinction between the above alternatives lies in the type of memory code assumed to represent abstract and concrete information in long-term memory. On the one hand, the codes could be effectively identical (e.g., an amodal code or an imagery code) or they could be distinct, but with parallel analog characteristics. Unfortunately, it is not possible to distinguish among the alternatives on the basis of the present data. However, any number of established techniques could be employed in future research to disentangle the above possibilities. For example, a Brooks selectiveinterference paradigm (Brooks, 1968) could be used to determine whether abstract and concrete information is processed using the same "modality." Similarly, if a lateralization difference (i.e., increased RTs for verbal or visual-spatial hemisphere presentations) were observed for concrete and abstract decisions, then this would offer strong support for a dual-code model (e.g., Seamon \& Gazzaniga, 1973).

\section{REFERENCES}

Brooks, L. R. Spatial and verbal components of the act of recall. Canadian Journal of Psychology, 1968, 22, 349-368.

Curtis, D. W., Paulos, M. A., \& Rule, S. J. Relation between disjunctive reaction time and stimulus difference. Journal of Experimental Psychology, 1973, 99, 167-173.

Holyoak, K. J., \& WalKer, J. H. Subjective magnitude information in semantic orderings. Journal of Verbal Learning and Verbal Behavior, 1976, 15, 287.299.

MOYER, R. S. Comparing objects in memory: Evidence suggesting an internal psychophysics. Perception \& Psychophysics, 1973, 13, 180-184.

Moyer, R. S., \& BAyer, R. H. Mental comparison and the symbolic distance effect. Cognitive Psychology, 1976, 8, 228-246.

MYers, J. L. Fundamentals of experimental design. Boston: Allyn \& Bacon, 1966.

PaIvio, A. Imagery and verbal processes. New York: Holt, Rinehart, \& Winston, 1971.

Paivio, A. Language and knowledge of the world. Educational Researcher, 1974, 3, 5-12.

Paivio, A. Perceptual comparisons through the mind's eye. Memory \& Cognition, 1975, 3, 635-647.

Paivio, A., Yuille, J. C., \& Madigan, S. Concreteness, imagery, and meaningfulness values for 925 nouns. Journal of Experimental Psychology Monograph Supplement, $1968,76(1$, Part 2), 1-25.

Potrs, G. R. Information processing strategies used in the encoding of linear orderings. Journal of Verbal Learning and Verbal Behavior, 1972, 11, 727-740.

Potтs, G. R. Storing and retrieving information about ordered relationships. Journal of Experimental Psychology, 1974, 103, 431-439.

Seamon, J. J., \& Gazzaniga, M. S. Coding strategies and 
cerebral laterality effects. Cognitive Psychology, 1973, 5, 249-256.

SHEPARD, R. N. Form, formation, and transformation of internal representations. In R. L. Soslo (Ed.), Information processing and cognition: The Loyola symposium. Hillsdale, N.J: Lawrence Erlbaum, 1975. Pp. 87-122.

Shepard, R. N., \& Chipman, S. Second-order isomorphism of internal representations: Shapes of states. Cognitive Psychology, 1970, 1, 1-17.

Shepard, R. N., \& Podgorny, P. Cognitive processes that resemble perceptual processes. In W. K. Estes (Ed.), Handbook of learning and cognitive processes. New York: Academic Press, in press.

Trabasso. T., \& Riley, C. A. The construction and use of representations involving linear order. In R. L. Soslo (Ed.), Information processing and cognition: The Loyola symposium. Hillsdale, N.J: Lawrence Erlbaum, 1975, $381-410$.

\section{NOTES}

1. The present experiment was conducted without knowledge of the Holyoak and Walker (1976) study.

2. In some earlier studies (cf. Shepard \& Podgorny, in press) mean RT was observed to be a logarithmic rather than linear function of the distance between items. This possibility was examined in the present data by correlating the mean RT for each of the 15 pairs with the log-interval distance across all categories. No systematic improvement in the mean correlations was observed when $\log$ functions were used $(-.68$ and -.74 for abstract and concrete judgments, respectively), rather than linear functions $(-.66$ and -.75 , respectively $)$.

(Received for publication August 4, 1976; revision received November 16,1976 .) 